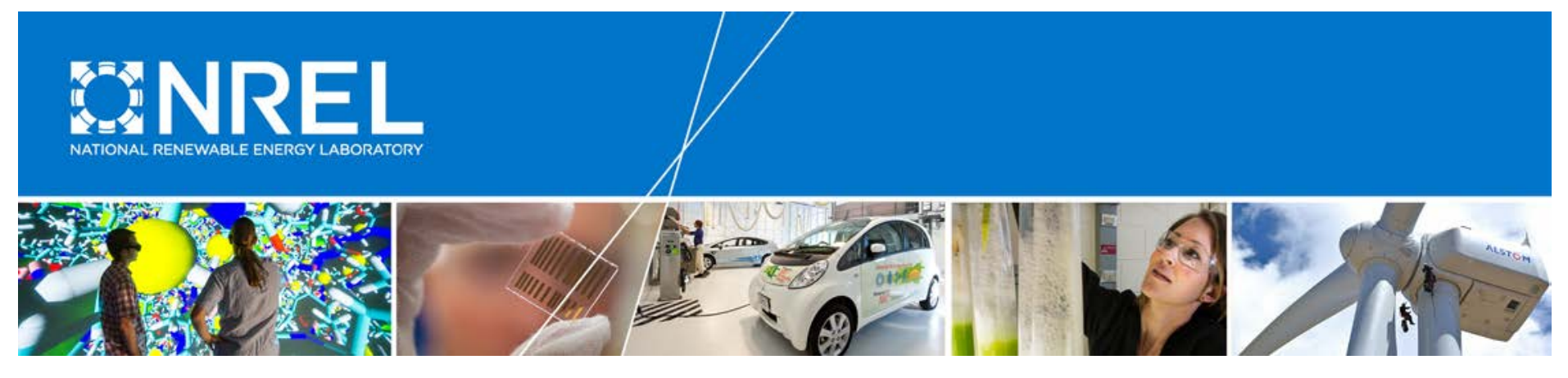

\title{
Clear-Sky Probability for the August 21, 2017, Total Solar Eclipse Using the NREL National Solar Radiation Database
}

Steve Wilcox, ${ }^{1}$ Aron Habte, ${ }^{2}$ Billy Roberts, ${ }^{2}$ Tom Stoffel, ${ }^{1}$ Mark Kutchenreiter, ${ }^{2}$ and Manajit Sengupta ${ }^{2}$

${ }^{1}$ Solar Resources Solutions, LLC

${ }^{2}$ National Renewable Energy Laboratory

NREL is a national laboratory of the U.S. Department of Energy Office of Energy Efficiency \& Renewable Energy Operated by the Alliance for Sustainable Energy, LLC

This report is available at no cost from the National Renewable Energy Laboratory (NREL) at www.nrel.gov/publications.

Technical Report

NREL/TP-5D00-68885

July 2017 


\section{Clear-Sky Probability for the August 21, 2017, Total Solar Eclipse Using the NREL National Solar Radiation Database}

Steve Wilcox, ${ }^{1}$ Aron Habte, ${ }^{2}$ Billy Roberts, ${ }^{2}$ Tom Stoffel, ${ }^{1}$ Mark Kutchenreiter, ${ }^{2}$ and Manajit Sengupta ${ }^{2}$

${ }^{1}$ Solar Resources Solutions, LLC

${ }^{2}$ National Renewable Energy Laboratory

Prepared under Task No. STS6.0810

NREL is a national laboratory of the U.S. Department of Energy Office of Energy Efficiency \& Renewable Energy Operated by the Alliance for Sustainable Energy, LLC

This report is available at no cost from the National Renewable Energy Laboratory (NREL) at www.nrel.gov/publications.

\section{Technical Report}

NREL/TP-5D00-68885

July 2017

Contract No. DE-AC36-08GO28308
National Renewable Energy Laboratory 15013 Denver West Parkway Golden, CO 80401

303-275-3000 • www.nrel.gov 


\section{NOTICE}

This report was prepared as an account of work sponsored by an agency of the United States government. Neither the United States government nor any agency thereof, nor any of their employees, makes any warranty, express or implied, or assumes any legal liability or responsibility for the accuracy, completeness, or usefulness of any information, apparatus, product, or process disclosed, or represents that its use would not infringe privately owned rights. Reference herein to any specific commercial product, process, or service by trade name, trademark, manufacturer, or otherwise does not necessarily constitute or imply its endorsement, recommendation, or favoring by the United States government or any agency thereof. The views and opinions of authors expressed herein do not necessarily state or reflect those of the United States government or any agency thereof.

This report is available at no cost from the National Renewable Energy Laboratory (NREL) at www.nrel.gov/publications.

Available electronically at SciTech Connect http:/www.osti.gov/scitech

Available for a processing fee to U.S. Department of Energy and its contractors, in paper, from:

U.S. Department of Energy

Office of Scientific and Technical Information

P.O. Box 62

Oak Ridge, TN 37831-0062

OSTI http://www.osti.gov

Phone: 865.576.8401

Fax: 865.576.5728

Email: reports@osti.gov

Available for sale to the public, in paper, from:

U.S. Department of Commerce

National Technical Information Service

5301 Shawnee Road

Alexandria, VA 22312

NTIS http://www.ntis.gov

Phone: 800.553 .6847 or 703.605 .6000

Fax: 703.605.6900

Email: orders@ntis.gov 


\section{Acknowledgments}

This work was supported by the U.S. Department of Energy under Contract No. DE-AC36-08GO28308 with the National Renewable Energy Laboratory (NREL). The authors would like to acknowledge Dr. Yu Xie of NREL's Sensing, Measurement, and Forecasting Group; and Anthony Lopez of NREL's Data Analysis and Visualization Group, for reviewing and providing input to this work. We also gratefully acknowledge Katie Wensuc, technical editor with NREL Communications, for her continuous support in the publication process. 


\section{List of Acronyms}

DNI

FARMS

GOES

NREL

NSRDB
Direct normal irradiance

Fast All-Sky Radiation Model for Solar

Applications

Geostationary Operational Environmental Satellite

National Renewable Energy Laboratory

National Solar Radiation Database 


\section{Executive Summary}

The National Renewable Energy Laboratory (NREL) and collaborators have created a clear-sky probability analysis to help guide viewers of the August 21, 2017, total solar eclipse, the first continent-spanning eclipse in nearly 100 years in the United States. Using cloud and solar data from NREL's National Solar Radiation Database (NSRDB), the analysis provides cloudless sky probabilities specific to the date and time of the eclipse. Although this paper is not intended to be an eclipse weather forecast, the detailed maps can help guide eclipse enthusiasts to likely optimal viewing locations. Additionally, high-resolution data are presented for the centerline of the path of totality, representing the likelihood for cloudless skies and atmospheric clarity. The NSRDB provides industry, academia, and other stakeholders with high-resolution solar irradiance data to support feasibility analyses for photovoltaic and concentrating solar power generation projects. 


\section{Table of Contents}

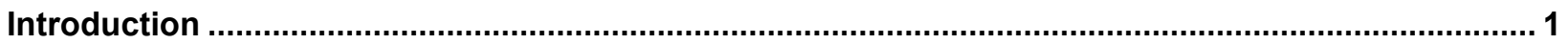

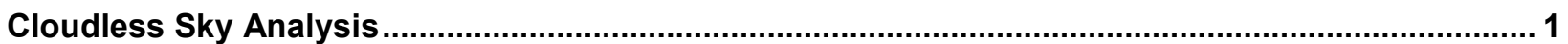

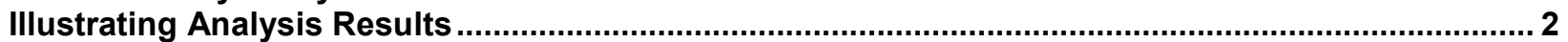

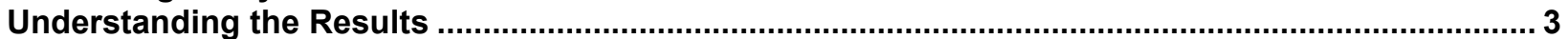

The National Solar Radiation Database ................................................................................... 4

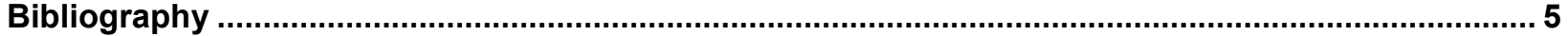




\section{List of Figures}

Figure 1. Cloudless-sky probabilities for August 21, 2017, and path of total solar eclipse. Cartography by Billy J. Roberts, NREL. .......................................................................................... 2

Figure 2. Centerline profile of the path of total solar eclipse. ${ }^{2}$ Cartography by Billy J. Roberts, NREL..... 3 


\section{Introduction}

On August 21, 2017, the United States will experience a total solar eclipse, with the sun's disk completely blocked, an event not seen in the United States since 1979, when viewing was limited to the extreme northwestern states. The 2017 eclipse will move across the entire width of the United States, carving an arc of totality through portions of Oregon, Idaho, Wyoming, Nebraska, Kansas, Missouri, Illinois, Kentucky, Tennessee, Georgia, North Carolina, and South Carolina. Such a vast expanse of the United States has not seen an eclipse in nearly 99 years, likely beyond the memory of nearly everyone alive today.

\section{Cloudless Sky Analysis}

Clouds have forever been the bane of eclipse watchers because even a single small cloud can obscure the view at a particular location during the totality of an eclipse, which could last a scant 2 minutes and 40 seconds at the longest in a particular location (only 2 minutes in some locations). However, the 2017 eclipse passes through many U.S. climate zones, increasing the likelihood of clear skies somewhere along the path. The holy grail of eclipse watchers is to set up under clear skies, but that becomes an elusive goal because clouds are among the most difficult weather elements to predict more than a few hours in advance with any certainty. Unfortunately, even a reliable short-term forecast might not suffice because heavy traffic on the day of the eclipse could hinder the travel required to quickly relocate some distance beyond the effects of a weather system.

But given historical climate data, a reliance on the probability of clear skies is an informed starting point for selecting a worthwhile location. The analysis shown here takes a focused statistical approach to determine the likelihood of clear skies at any location along the path of totality for the 2017 solar eclipse. Using explicit cloud data available in the National Solar Radiation Database (NSRDB) from the National Renewable Energy Laboratory (NREL), we selected a narrow sample of data for analysis. In addition to solar irradiance estimates, the NSRDB provides cloud type estimates for much of North America, Central America, and South America at intervals of $0.04^{\circ}$ latitude and longitude for each half hour from 1998-2015. Among the cloud type values designated in the NSRDB are "clear" and "probably clear," which are wellsuited to the needs of eclipse watchers.

For this analysis to account for the average 3-day life cycle of large weather systems, we chose the three half-hour designations closest to the actual local eclipse times for the 5 days on either side of August 21 for each of the 18 years of the NSRDB. The short 1-hour window around the eclipse time is necessary because of the effects of daily weather patterns that exist in many locations. For example, one time of day might be typically clear, but the sky might become cloudy 2 or 3 hours later. This approach helps isolate the effects to the local time of the eclipse. For each pixel (approximately $4 \mathrm{~km}$ by $4 \mathrm{~km}$ in coverage), approximately 600 values form a sample representing an acceptable range of weather conditions specific to that location. From that pool the frequency of the two clear-sky designations determines a cloudless-sky probability for each pixel.

One captivating feature of a solar eclipse is the appearance of planets and stars during totality. As with nighttime viewing of stars, the more clear the atmosphere, the greater the number of other celestial objects that will be visible during totality. Because atmospheric components other than clouds, such as water vapor and aerosols, can affect atmospheric clarity, we extracted the coincident direct normal irradiance (DNI) solar values from the NSRDB. DNI represents sunlight traveling directly from the sun through the atmosphere. The magnitude of the DNI in 
cloudless skies provides some measure of atmospheric clarity, which can serve to characterize atmospheric conditions at the time of the eclipse for each pixel location. Toward this end, we provide the average DNI specific to cloudless conditions as another factor to consider when choosing a viewing location.

\section{Illustrating Analysis Results}

The August 21 cloudless-sky probabilities for the contiguous United States are mapped in Figure 1. The path of totality, ${ }^{1}$ which is of greatest interest to serious eclipse watchers, is shown by the dashed lines. The total eclipse occurs only within the bounds of this path. The longest duration of the eclipse will occur along the center line of the path of totality, which is shown on the map as a solid line.

Figure 2 shows the path of totality shown in Figure 1, but it also includes a corresponding graph of cloudless-sky probabilities and average DNI profiles by longitude along the centerline of totality. Using this information, eclipse watchers can find coincident occurrences by region of high probability for cloudless skies with high DNI to optimize the search for a viewing location. The most important factor by far in this analysis is the probability of cloudless skies, which should be the primary consideration when selecting a site. High DNI, representing atmospheric clarity, is a secondary concern.

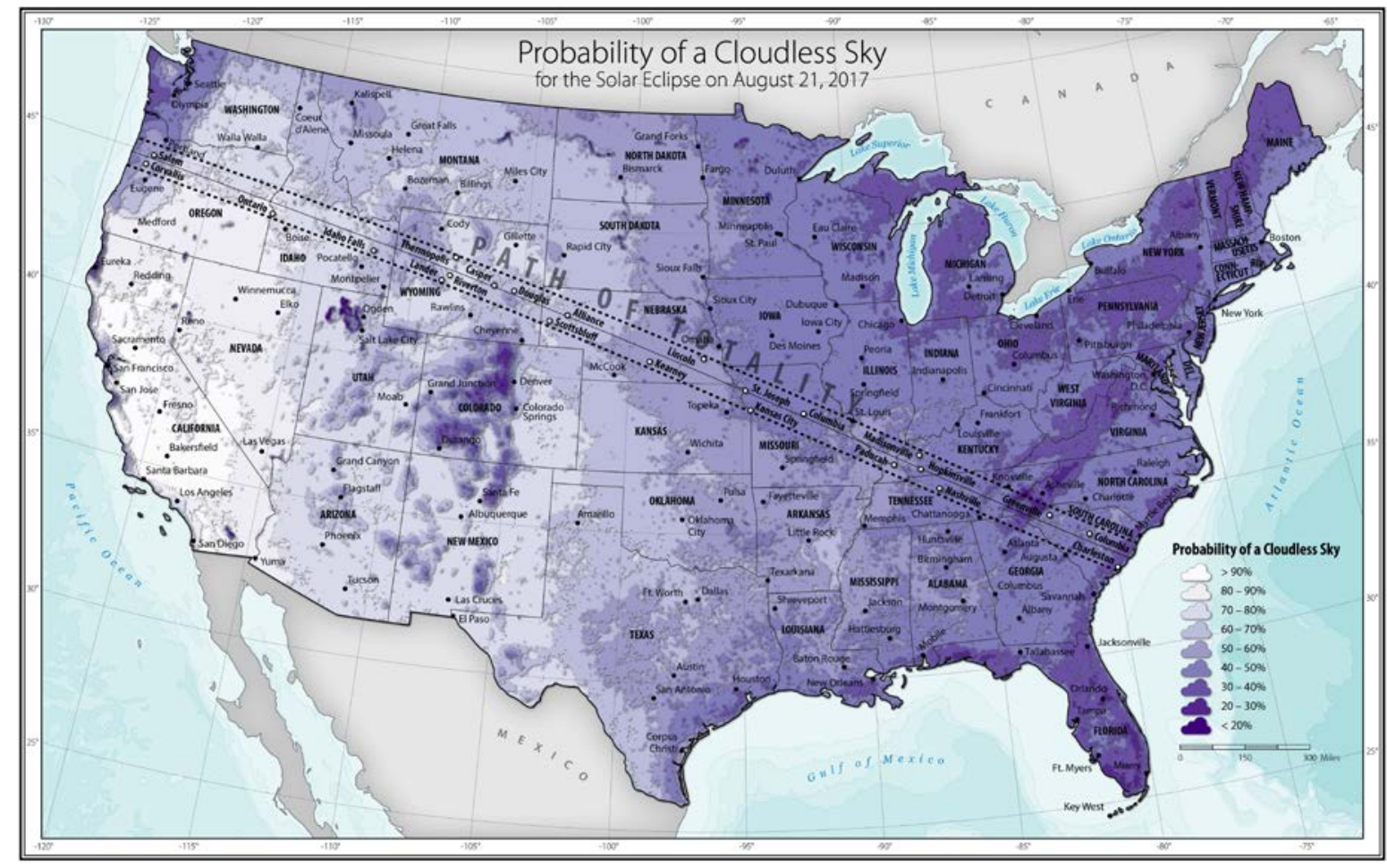

Figure 1. Cloudless-sky probabilities for August 21, 2017, and path of total solar eclipse. ${ }^{2}$ Cartography by Billy J. Roberts, NREL.

(Please see the full-size map for Figure 1 attached to this PDF.)

\footnotetext{
${ }^{1}$ See https://eclipse.gsfc.nasa.gov/eclipse.html.

${ }^{2}$ Path of totality from Eclipse Predictions by Fred Espenak, NASA/GSFC Emeritus.
} 


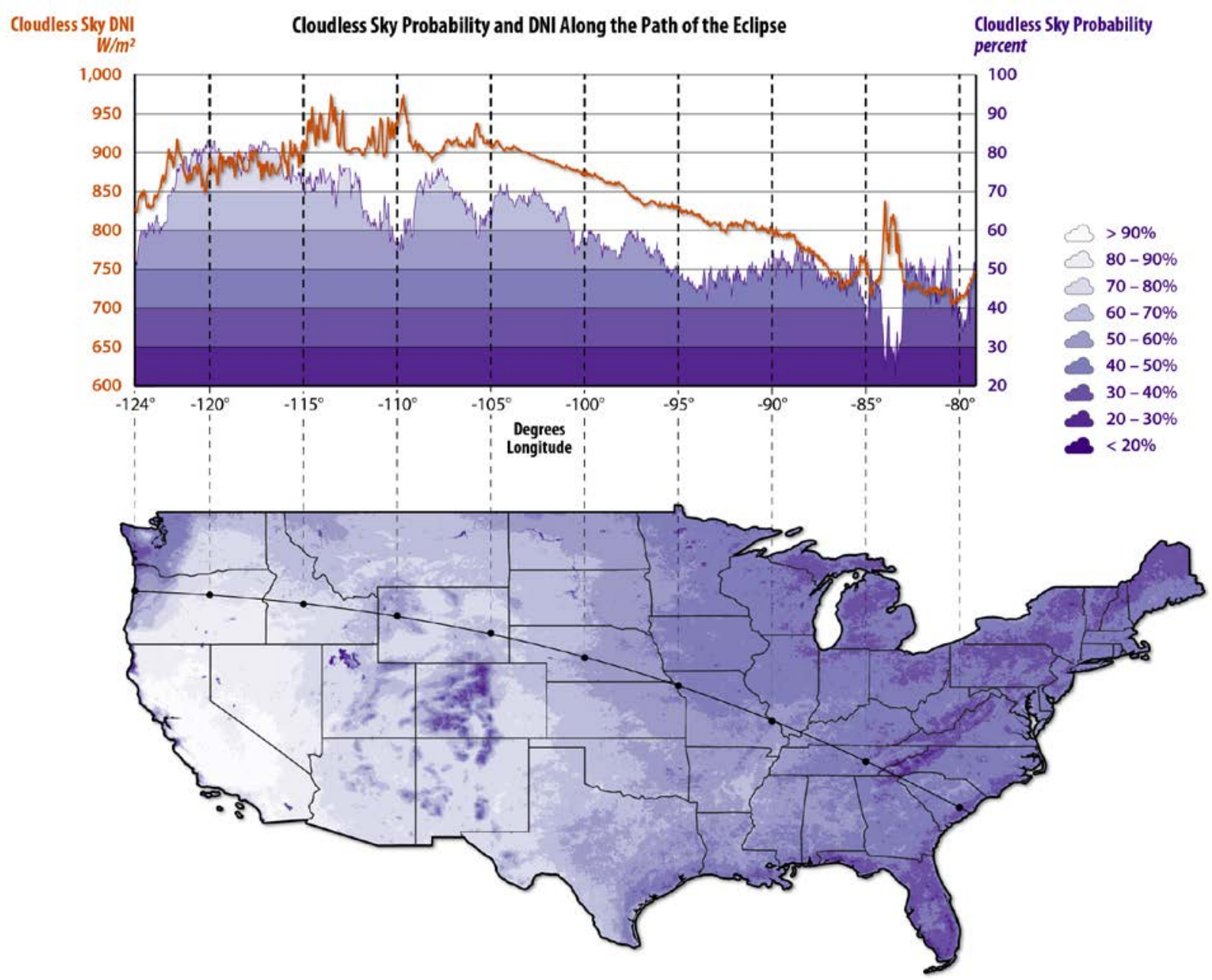

Figure 2. Centerline profile of the path of total solar eclipse. Cartography by Billy J. Roberts, NREL.

(Please see the full-size map for Figure 2 attached to this PDF.)

\section{Understanding the Results}

Although interpreting the eclipse maps is straightforward, applying the information to find the best viewing location must be accompanied by strong caveats. Not the least of these caveats is that the clear-sky probability for any location is rendered irrelevant by actual conditions as the moment of totality approaches. For most pixels, the sample cloud values in this analysis range from overcast to clear, hence any sky condition is possible at any location. Thus, these probabilities are not a guarantee or a forecast, and in the final analysis there is no arguing with the weather! However, if an eclipse watcher has the flexibility to travel on or before the eclipse day, these maps could help them select a primary viewing location and several alternatives. As the day of the eclipse approaches, these maps, coupled with short-range weather forecasts, can provide useful location information to maximize the likelihood of viewing the total solar eclipse in clear skies. 


\section{The National Solar Radiation Database}

The source data for this analysis, the 1998-2015 NREL NSRDB, provides industry, academia, and other stakeholders with high-resolution solar irradiance data to support feasibility analyses for photovoltaic and concentrating solar power generation projects. Improved satellite-based solar irradiance models are essential to increasing the deployment of solar energy conversion systems and to understanding system efficiencies of existing installations. In particular, the improved solar resource data will reduce the financial risks presently associated with the design, deployment, and routine operations of utility-scale solar energy conversion systems. NREL, the University of Wisconsin, and the National Oceanic and Atmospheric Administration collaborated to develop a 4-km by 4-km product for the Geostationary Operational Environmental Satellite (GOES) coverage region using the Fast All-Sky Radiation Model for Solar Applications (FARMS) as the underlying radiative transfer model. The NSRDB uses a two-stage scheme to first retrieve cloud properties and then use those properties in FARMS to calculate surface radiation. The project creates a half-hourly, 4-km gridded solar irradiance product of known quality and accuracy for use in the database. 


\section{Bibliography}

National Aeronautics and Space Administration. 2017. "NASA Eclipse Web

Site." https://eclipse.gsfc.nasa.gov/eclipse.html.

National Renewable Energy Laboratory. 2017. "National Solar Radiation

Database." http://nsrdb.nrel.gov/. 